\title{
Aspectos sobre a visão humana em uma abordagem interdisciplinar no ensino médio
}

André L. M. de Barcellos Coelho ${ }^{1}$

Secretaria de Educação do Distrito Federal

Brasília - DF

\section{Resumo}

Inspirado na leitura de Japiassu (1976) sobre interdisciplinaridade, este trabalho explora a possibilidade de uma abordagem psicobiofísica no estudo da visão humana em salas de aula de ensino médio, dentro do contexto da disciplina de fisica. Uma abordagem que se vale de conhecimentos das neurociências (relação entre processos bioquímicos e o processamento visual), da biologia (sobretudo a teoria da evolução biológica) e da física (interação luz-matéria). Isto é feito de maneira tal que a compreensão sobre os conceitos físicos concernentes à física ondulatória seja indispensável. Como eixo integrador dessa abordagem, utilizamos a teoria da evolução biológica que se entende ser a teoria mais adequada para se compreender a complexidade que envolve o funcionamento da visão humana. Aproveito o ensejo para elencar alguns conceitos centrais desta teoria (tais como seleção natural, população, indivíduo, fenótipo, genótipo) com a finalidade de estabelecer base suficientemente sólida para que um professor de física que atue no ensino médio seja capaz de promover uma discussão competente sobre o tema.

Palavras-chave: Ensino de Física; Teoria da Evolução; Física da Visão.
Abstract

Inspired by Japiassu's (1976) reading on interdisciplinarity, this work explores the possibility of a psychobiophysical approach in the study of

\footnotetext{
Recebido: 24 de agosto de 2020.

Aceito: 9 de março de 2021.

* Aspects of human vision in an interdisciplinary approach in high school

${ }^{1}$ E-mail: prof.barcellos@hotmail.com
} 
human vision in high school classrooms, within the context of the discipline of physics. An approach that draws on knowledge from neurosciences (the relationship between biochemical processes and visual processing), biology (especially the theory of biological evolution) and physics (light-matter interaction). This is done in such a way that an understanding of the physical concepts concerning wave physics is indispensable. As an integrating axis of this approach, we use the theory of biological evolution which is understood to be the most adequate theory to understand the complexity that involves the functioning of human vision. I take the opportunity to list some central concepts of this theory (such as natural selection, population, individual, phenotype, genotype) in order to establish a solid enough basis for a physics teacher working in high school to be able to promote a competent discussion about the subject.

Keywords: Physics Teaching; Theory of Evolution; Physics of Vision.

\section{Introdução}

O ensino médio no Brasil foi, até meados da década de 80 , um segmento elitista e estruturado para cumprir o papel de mera transição para o nível superior. As políticas públicas destinadas exclusivamente a esse segmento só começam a ser implementadas na década de 90 e, aliadas ao esforço de democratizar o acesso ao ensino fundamental, culminaram na expansão vertiginosa do ensino médio (CASTRO, 2004). Entretanto, essa expansão súbita não foi compatível com poder adaptativo da estrutura educacional brasileira à nova realidade iminente, desde a formação de professores até a implementação das recomendações de documentos reguladores como os Parâmetros Curriculares Nacionais ( $\mathrm{PCN}$ e $\mathrm{PCN}+$ ) e a Lei de Diretrizes e Bases da Educação Brasileira (LDB). Essa incompatibilidade acabou por gerar uma escola média de transição que até hoje não é capaz de articular plenamente seus conteúdos e métodos com as demandas imediatas de seus estudantes.

Nos Parâmetros Curriculares Nacionais há, em diversas oportunidades, argumentos dissuadindo a escola média a fornecer um ensino preparatório e que pouco contribui para a formação de um cidadão consciente e plenamente integrado na sociedade. A interdisciplinaridade e a multidisciplinariedade prevista nestes documentos são alguns dos argumentos mais veementemente contrários à educação propedêutica, já que forneceriam aos estudantes a oportunidade de um ensino não segmentado e integrado ao seu cotidiano social (BRASIL, 1999).

Sob esse escopo, o presente trabalho vem enaltecer uma possibilidade de trabalho interdisciplinar entre os componentes curriculares de Física e Biologia no ensino médio. Mais precisamente, no segundo ano, quando se leciona, tradicionalmente, física ondulatória. Nesta 
ocasião, é conceituada a onda eletromagnética - e luz como um exemplo canônico -, em geral, de maneira postular. Isto se deve, talvez, pela herança histórica que advém do desenvolvimento do eletromagnetismo com Maxwell no século XIX (ABRANTES, 1988) ou pelo risco de incorrer em equívocos conceituais ao abrir mão do uso de uma matemática que foge do domínio de estudantes do ensino médio, em geral.

A despeito das discussões epistemológicas das teorias físicas acerca dos fenômenos eletromagnéticos (e/ou em óptica geométrica), acredito que na oportunidade do desenvolvimento do conceito ondulatório de onda eletromagnética possa ser realizada uma discussão sobre a evolução biológica e o funcionamento da visão humana na qual a compreensão do conceito físico de luz seja imprescindível. É justamente sobre isso que trata este trabalho.

Tal proposta ataca dois problemas no ensino médio brasileiro: (i) a segmentação do conhecimento escolar e (ii) a negligência de demandas prementes dos estudantes envolvidos no processo educacional. O problema (i) é trabalhado ao desenvolver uma abordagem interdisciplinar que forneça a conscientização de que fenômenos complexos, como a visão humana, só são satisfatoriamente compreendidos uma vez que sejam articulados conhecimentos de áreas diversas, como a biologia, a física e a neuropsicologia. Dessa forma, fornece-se um exemplo de que o conhecimento científico não é sempre segmentado e que, de fato, precisa se articular para descrever fenômenos complexos. Já o problema (ii) é enfrentado na medida em que essa natureza de discussão tem potencial de realizar mudanças de ordem epistemológica/gnosiológica (e até ontológicas) na percepção dos estudantes em relação a fenomenologia natural (DOS SANTOS, 2012; AULER, 2001).

Reconhecemos que o termo interdisciplinaridade é demasiado polissêmico como alerta (ZIMMERMANN; CARLOS, 2005.). Consciente disso, sempre tivemos em mente o conceito de interdisciplinaridade trazido por Japiassú "Interdisciplinaridade e patologia do saber"

Podemos dizer que nos reconhecemos diante de um empreendimento interdisciplinar todas as vezes em que ele conseguir incorporar os resultados de várias especialidades, que tomar de empréstimo à outras disciplinas certos instrumentos e técnicas metodológicos, fazendo uso dos esquemas conceituais e das análises que se encontram nos diversos ramos do saber, a fim de fazê-los integrarem e convergirem [...] (Japiassú, 1976, p. 74 e 75).

Tivemos este conceito em mente no desenvolvimento deste trabalho pelo pragmatismo derivado a esta conceituação. Pragmatismo este que encontra eco na nossa prática docente cotidiana. Além disso, alinhamo-nos ao trabalho de Zimmermann e Carlos (2005) que dizem que:

\footnotetext{
${ }^{2}$ Obra responsável por popularizar o uso do termo no Brasil.
} 
Num mundo complexo onde o conhecimento especificamente disciplinar começa a revelar-se insuficiente para o trato de problemas tanto de ordem social, quanto natural, a interdisciplinaridade parece encontrar um terreno fértil para se desenvolver (ZIMMERMANN; CARLOS, 2005).

A visão humana é um complexo sistema que envolve processos físicos, químicos, biológicos e de natureza psico-neuronal. Por isso, é possível pensá-lo como um problema de caráter eminentemente interdisciplinar. De onde deriva que uma caracterização puramente mecânica do processo pelo qual a luz é submetida quando no olho é tão somente uma pequena fração da descrição do fenômeno da visão. Para uma satisfatória descrição do fenômeno há de se considerar, por exemplo, os processos bioquímicos da fototransdução que envolve diversos mecanismos biológicos que convertem a luz em impulsos elétricos legíveis ao cérebro. $\mathrm{E}$ mais, mesmo acrescentando a compreensão das proteínas fotorreceptoras e os seus processos biológicos, a compreensão do porque enxergamos o que enxergamos deve incluir o que acontece na interação olho-cérebro (NASSAU, 2001). Está sediado no cérebro a percepção de cores e contrastes que não necessariamente refletem a realidade física do que se está vendo (SCARINCI, 2014).Uma vez posta a problemática, resta a dúvida: por qual motivo nosso sistema visual (olho-cérebro) é como é? Parece estar bem estabelecido que problemas dessa natureza só podem ser resolvidos à luz da teoria da evolução (MAYR, 2009).

Neste trabalho se pretende fornecer subsídios para que uma discussão competente acerca dessa problemática possa ser realizada em salas de aula de ensino fundamental e médio. Não se propõe, entretanto, um método pelo qual isso seja viabilizado, ficando a cargo dos próprios educadores a realização dessa tarefa. Para tanto, traremos alguns conceitos fundamentais da teoria da evolução biológica (na seção 2). Em seguida, descreveremos a fototransdução demonstrando a crescente complexidade do fenômeno e sua consequente compreensão (seção 3). Focamos em um aspecto particular da visão humana: a interação entre luz e matéria na percepção das cores e na sensibilidade da luz incidente.

\section{Conceitos centrais da Teoria da Evolução}

A teoria da evolução das espécies, de Charles Darwin, proposta em 1859, acumulou, ao longo de pelo menos oito décadas após sua publicação, diversas evidências que a consolidaram como um fato (MAYR, 2009). Ela não só impulsionou a criação e desenvolvimento de diversas áreas dentro da grande área da Biologia, como também subsidiou surpreendentes descobertas como as de uma origem comum e única de toda a vida na Terra. Entretanto, a despeito de sua inegável importância, ela vem sendo mal difundida e vitimada por uma série de má compreensão em relação à sua estrutura e conceitos básicos (TIDON, 2009; BIZZO, 2009). Portanto, faz-se oportuno elucidar e enunciar alguns conceitos centrais dessa teoria.

Anteriormente a Darwin, várias teorias da evolução foram propostas. Fortemente 
influenciadas, em especial, pela ontologia cristã, eram teorias essencialmente teleológicas. Herdada de Aristóteles e amplamente aceita até meados do século XIX, o essencialismo balizava teorias dessa natureza. Como exemplo, cito o transmutacionismo que defendia a ideia de que existem essências constantes para cada espécie (origem múltipla das espécies) e que a evolução acontece, na verdade, por saltos que seriam capazes de transmutar a essência original e dar origem a uma completamente diferente. Essa tese era corroborada por numerosas observações de descontinuidade na natureza.

A descoberta de ancestralidade comum a espécies diferentes acabou por falsear a teoria transmutacionista, o que logo deu origem a uma segunda teoria evolucionista, também teleológica, conhecida como transformacionismo. Os transformacionistas reconheciam que a evolução, de fato, era gradativa e não oferecia saltos repentinos, entretanto não abandonaram a ideia da existência de arquétipos imutáveis, ou essências imutáveis. Um importante marco do desenvolvimento dessa teoria é o trabalho de Lamarck. Nele é defendido que "as adaptações sofridas pelas espécies advém do uso e do desuso de um órgão ou a influência direta do meio sobre o material genético" (MAYR, 2009).

É nesse contexto de teorias que defendiam que a evolução acontece direcionalmente e conduzem as espécies a serem cada vez mais perfeitas (daí a alcunha de "finalistas", ou seja, a evolução acontece para atingir um determinado fim preconcebido) que ganha força a teoria darwiniana para a evolução. Fundamentalmente, ele busca responder: (i) que ente evolui na natureza e (ii) por quais mecanismos ela é viabilizada.

Para Darwin, são as populações que evoluem e não o indivíduo, isto é, as mudanças fenotípicas e/ou genotípicas que acontecem em um espécime único não podem ser chamadas de evolução, no sentido literal da teoria. Vale a menção de que a teoria que Darwin originalmente formulou para a evolução biológica não estava relacionada com a genética moderna. Esta relação só acontece muito mais recentemente com teorias como a Teoria Sintética Moderna e a Síntese Evolutiva Estendida (CESCHIM, 2016). A segunda questão levantada é respondida observando que as espécies são mutáveis (o que é condição sine qua non para uma teoria de evolução, diga-se). De geração a geração acontecem diversas variações que podem ou não produzir indivíduos mais adaptados a condições ambientais. Aqueles que, por acaso, desenvolverem maior adaptabilidade, acabam sendo selecionados por um processo conhecido como seleção natural e tendem a perpetuar essa característica.

Adicionalmente a biologia genética, modernamente, nos ajudou a entender que é o fenótipo que sofre a ação da seleção natural e não o genótipo. Vários genes são quase imutáveis ao longo da evolução - inclusive essa observação corrobora a tese da origem comum das espécies (alguns genes são comuns a humanos, macacos e até a moscas). Contudo, a cada nova geração, uma determinada parcela de uma população demonstra variabilidades (mutações) genéticas que podem - ou não - gerar um fenótipo mais adaptado. Por conseguinte, observa-se essa característica genética modificada sendo perpetuada.

Aparentemente há sistemas mais sensíveis à seleção natural que outros. Como se 
demonstra no trabalho de Dolgin (2015), nossa visão é particularmente sensível a mudanças ambientais. Ao estudar sobre o crescimento explosivo de ocorrência de miopia, verificou-se que não há uma forte correlação genética com o evento. Enquanto que o índice de ocorrência da miopia chega a $90 \%$ da população jovem em determinadas regiões da Ásia, na comunidade inuit no Canadá, por exemplo, esse índice não chega a 10\% (MORGAN, 1975). Isso não aconteceria se a miopia fosse uma doença puramente genética.

Uma das hipóteses mais aceitas para explicar esse fenômeno é a de que passamos a ficar muito mais tempo em ambientes fechados e o hábito de utilizar a visão para ver objetos mais próximos pode ter sido um fator determinante para o desenvolvimento de uma visão míope (DOLGIN, 2015). Outra hipótese levantada é a de que a ausência à exposição solar, de alguma maneira, diminuiria a capacidade de acomodação visual, o que acarretaria no desenvolvimento da doença (NGO, 2013). Seja como for, esse é um exemplo de que a evolução não acontece no genótipo, mas ao invés disso, no fenótipo.

\section{Visão Humana: uma descrição multidisciplinar}

De maneira simplificada, nossa visão funciona do seguinte modo: a luz que incide sobre a superfície externa de nossos olhos é primeiramente ponderada pela pupila, que regula a entrada de luz, tal como uma persiana. Depois, a luz refratada incide sobre o cristalino que se trata de uma lente que converge os raios luminosos sobre uma estrutura conhecida como retina, que está localizada na parte posterior dos olhos. Esta última estrutura, é um tecido especializado onde se encontra dois tipos de células fotossensíveis, chamadas cones e bastonetes. Essas células convertem o estímulo luminoso em impulsos elétricos (processo que é conhecido como fototransdução) que são conduzidos para o cérebro através do nervo óptico.

Este funcionamento envolve uma descrição física da interação entre onda eletromagnética e matéria, a compreensão dos mecanismos bioquímicos que realizam, de fato, a fototransdução, além de aspectos relacionados ao neuroprocessamento de imagens (NASSAU, 2001).

\section{III.1 Fototransdução}

O processo de fototransdução começa a acontecer nas referidas células fotossensíveis localizadas na retina, os cones e os bastonetes. Elas são células transmembranares responsáveis por converter estímulos luminosos em impulsos elétricos legíveis ao cérebro. $\mathrm{O}$ segmento externo dessas células está revestido por uma proteína fotossensível da classe das opsinas (proteínas fotossensíveis). No segmento interno da célula está localizado o núcleo celular e posteriormente os terminais sinápticos que compõem o nervo óptico. Vide Fig. 1. 


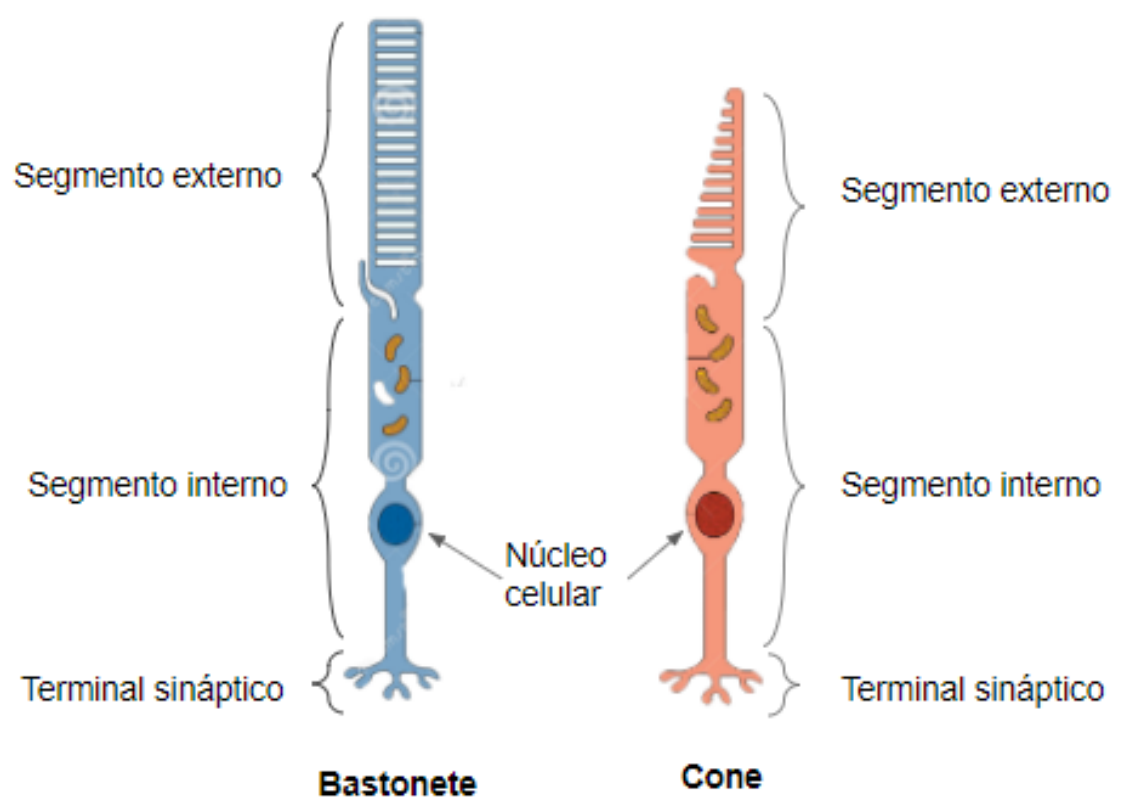

Fig. 1 - Representação dos cones e bastonetes. Os bastonetes levam esse nome por se assemelhar a um bastão (à esquerda) e os cones por seu formato cônico (à direita). Imagem produzida pelo autor a partir de um banco de imagens.

Em um olho saudável, há cerca de 150 milhões de receptores fotossensíveis, entre cones (5\% dos receptores, aproximadamente) e bastonetes (os 95\% restantes). Os bastonetes são revestidos por uma proteína em seu segmento externo, chamada rodopsina (também conhecida como RH1), que é extremamente sensível à luz. Elas são particularmente sensíveis ao comprimento de onda de cerca de $510 \mathrm{~nm}$ (PURKYNĚ, 1823). Já os cones, que são mais concentradas na região central da retina (chamada fóvea), são dotados de uma proteína diferente, a iodopsina, que é bem menos sensível (cerca de 1\% da sensibilidade da rodopsina). Apesar da pouca sensibilidade, há três tipos de cones que possuem sensibilidade máxima em diferentes comprimentos de onda (ligada a iodopsina para cada uma das três cores primárias ${ }^{3}$ encontra-se uma proteína diferente: para o comprimento de onda de 450nm a SWS1, para 530 $\mathrm{nm}$ a OPN1MW e para $565 \mathrm{~nm}$ a OPN1LW) (OYAMADA, 2015). Vide Fig. 2. Combinando esses estímulos, somos capazes de enxergar todo o espectro eletromagnético visível.

\footnotetext{
${ }^{3}$ Há uma concepção errônea e amplamente divulgada em livros didáticos e entre os professores de que enxergamos apenas três cores que, quando combinadas originam as outras cores do espectro visível. Essa concepção advém da compreensão parcial da nossa visão tricônica. Como é visto na imagem 2, de fato há três picos de sensibilidade na região do vermelho ou amarelo, no verde e no azul. Entretanto, como também é facilmente visto na referida figura, esses picos não são discretos e o que se observa é que, quando combinados, os estímulos reconhecidos pelos três cones são capazes de produzir uma visão que, de fato, "cobre" todo o espectro eletromagnético visível.
} 


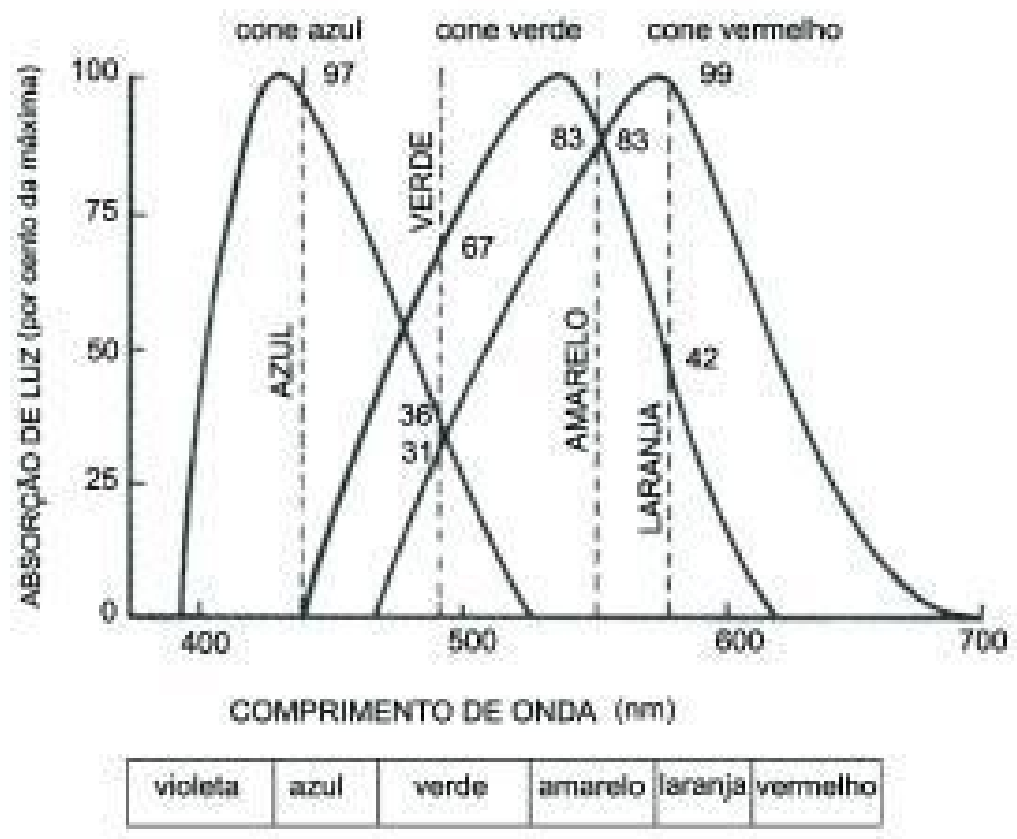

Fig. 2 - Absorção de luz em função do comprimento de onda para os três cones que compõem a visão humana (GUYTON, 2006).

Quando expostas à luz, a rodopsina e a iodopsina são degradadas gradualmente. Por isso, a função da pupila é extremamente importante: a de regular a entrada de luz que atinge os fotorreceptores. Sem esse controle eles seriam dessensibilizados rapidamente e perderíamos a capacidade de realizar a fototransdução, ainda que temporariamente. $\mathrm{O}$ processo de regeneração dessas proteínas pode levar cerca de 30 minutos para a rodopsina e, aproximadamente, 10 minutos para a iodopsina (OYAMADA, 2015).

Em um ambiente de baixa luminosidade, essa regeneração tende a ser mais abrangente, isto é, como há menos exposição à luz, menos proteínas são desativadas e observamos uma gradativa melhora da acuidade visual. Além disso, nossas pupilas tendem a dilatar-se, permitindo uma adequada entrada de luz. Entretanto, como os cones são muito menos sensíveis a luz do que os bastonetes (é necessário ativar cerca de 10 bastonetes para que a fototransdução aconteça, enquanto que para os cones esse número sobe para 400), não somos capazes de enxergar cores em ambiente de baixa luminosidade, efeito conhecido como efeito Purkinje.

O processo bioquímico pelo qual esses mecanismos funcionam é descrito no trabalho de Oyamada (OYAMADA, 2015) com detalhes. Em um ambiente de baixa luminosidade, a proteína rodopsina está ligada ao 11 -cis-retinal ${ }^{4}$. Ao absorver um fóton, por um processo de fotoisomerização, isomeriza-se para trans-retinal o que dá início ao processo da fototransdução propriamente dita. Um fotopigmento intermediário chamado metarodopsina II (ou $\mathrm{Rh}^{*}$ ) é então ativado para dar continuidade ao processo. Ele é importante, pois aumenta a

\footnotetext{
${ }^{4}$ O 11 -cis-retinal é uma forma isomerizada da vitamina A (trans-retinol).
} 
afinidade da rodopsina pela arrestina (proteína regulatória) que, por fim, atua formando os estímulos que serão conduzidos ao cérebro.

A referida regeneração dos fotorreceptores começa a acontecer após a inativação do Rh*. Essa inativação favorece, de algum modo, a redução do trans-retinal em trans-retinol e quebra a ligação com a arrestina. Então, ele é transportado para o segmento externo dos fotorreceptores na retina, onda é isomerizado novamente para sua forma 11-cis-retinol e oxidado para a forma 11-cis-retinal. Estando assim, pronto para uma nova fotossensibilização.

\section{III.2 Interação luz-matéria}

É comum que os professores de física expliquem parte da fototransdução, que diz respeito à interação entre luz e matéria, por sistemas ressonantes. As interações ressonantes são, de fato, vistas em diversos casos semelhantes como na absorção do infravermelho a nível molecular e na absorção do ultravioleta por elétrons. Entretanto, a luz visível possui energia muito baixa para interagir com a matéria na escala eletrônica e grande demais para interações na escala molecular. Por este motivo, uma interação ressonante do tipo luz-matéria não é apropriada, na maior parte dos casos. Recorre-se, portanto, a modelos de interação cargas elétricas ligadas e campo eletromagnético, tipicamente descritas pelo eletromagnetismo clássico.

Os primeiros modelos não ressonantes para a interação luz-matéria remontam ao início do século XX. O mais notório dentre estes modelos é conhecido como modelo DrudeLorentz. Este modelo, em síntese, trata da interação entre as partículas carregadas que compõem a matéria irradiada e ondas eletromagnéticas. Essas partículas ligadas são tratadas como sendo osciladores forçados (HECHT, 1988). Como na descrição mecânica de osciladores forçados, uma carga ligada também teria uma frequência natural de oscilação $\omega_{0}$. E assim como na mecânica clássica, a frequência de um oscilador forçado proveniente de diversas fontes simultâneas, pode ser descrito como o somatório de diversas frequências proveniente de fonte única e, então, superpor todas elas para que se obtenha uma solução final. Como demonstrado por Scarinci e Marineli (SCARINCI, 2014), a amplitude de cada oscilador depende da frequência natural de oscilação $\omega_{0}$, da frequência da onda incidente $\omega$, da massa $m$ da carga em oscilação e da força $F$ que a impele a oscilar. Ou seja:

$$
A=\frac{F_{0}}{m \cdot\left(\omega_{0}^{2}-\omega^{2}\right)}
$$

Este modelo, entretanto, não leva em conta que as frequências naturais de osciladores de sistemas de cargas ligadas são quantizadas. Isto é, $\omega_{0}$ assume apenas valores discretos.

No caso específico da sensibilização dos fotorreceptores, há um intrincado problema em termos de energia de ativação. Presumidamente, um fotorreceptor pode absorver um único fóton e o problema passa a se concentrar em responder à questão: como a absorção de um único fóton pode desencadear uma enorme resposta amplificada (LANGER, 1973).

A energia de cada fóton é determinada pela frequência da onda, pela relação 
$E=h . v$. Um único fóton na região de maior sensibilização do rodopsina $(500 \mathrm{~nm})$, por exemplo, tem energia na ordem de $10^{-3} \mathrm{eV}$, o que é insuficiente para realizar a isomerização ${ }^{5}$ da 11-cis-retinal para a trans-retinal. A hipótese mais provável apontada por Langer é a de que a absorção de um fóton pelo pigmento visual é capaz de polarizar a molécula produzindo, por conta dos íons de $\mathrm{Na}^{+}$presentes no meio circundante, a resposta amplificada.

Esta natureza de problemas é frequente em descrições bioquímicas para ativação de proteínas em geral. Alguns autores, como Heyes (HEYES, 2005) e Moser (MOSER, 2006), descrevem o tunelamento quântico como mecanismo responsável pela polarização de pigmentos visuais. De fato, há todo um campo de estudo - conhecido como biologia quântica - que propõe que mecanismos quânticos são alguns dos responsáveis por diversos processos biológicos, como mutação de DNA, atividade enzimática e a própria fotoisomerização relatada na seção anterior. O próprio Erwin Schrödinger escreveu sobre isso em seu livro "What is life?: The physical aspect of the living cell" (SCHRODINGER, 1946).

\section{III.3 Neuro processamento visual}

As bases conceituais das interações onda eletromagnética-matéria são bem estabelecidas, especialmente com o advento da mecânica quântica no século XX (OKUNO, 2016). Assim também, os mecanismos bioquímicos envolvidos na fototransdução. Entretanto, nenhum nem outro sozinho é capaz de explicar o porquê vemos o que vemos. É necessário investigar a sede na qual se desenvolve a visão: o cérebro. Para contextualizar essa problemática, cito o fenômeno do metamerismo. Este efeito foi descrito pela primeira vez por Michel Eugène Chevreul em 1855, data da publicação de seu livro Principles of harmony and contrast of colors, an their applications to the arts (em tradução livre: Princípios da Harmonia e do contraste das cores e suas aplicações nas artes) (CHEVREUL, 1855). Nele, o autor descreve que, a depender da saturação e luminosidade, é possível confundir o matiz das cores, ou seja, objetos que fisicamente emitem luz com comprimentos de onda distintos podem ser visualizados como objetos de mesma cor. A Fig. 3 ilustra esse efeito.

O metamerismo revela que nossa visão não mede e nem relaciona comprimentos de onda de maneira singular e inequívoca. Mas em vez disso, o que vemos poderíamos qualificar como sensação de cor (SANDOVAL, 1990). Isto é, quando dizemos sobre a cor de um determinado objeto devemos tomar o cuidado de elucidar se referimo-nos às frequências das ondas eletromagnéticas que por ele são emitidas ou reemitidas, ou se referimo-nos a sensação visual que nos é oferecida ao olhar para esse objeto a olho nu.

\footnotetext{
${ }^{5}$ Segundo Salvador e Usberco (2003) Isomeria é um "fenômeno caracterizado pela ocorrência de duas ou mais substâncias diferentes, que apresentam a mesma fórmula molecular, mas diferentes fórmulas estruturais". (SALVADOR; USBERCO, 2003 p. 551). No caso citado, ao sofrer isomerização o 11-cis-retinal precisa ganhar energia (por intermédio dos fótons) para se isomerizar em trans-retinal. Trata-se, portanto, do mesmo conjunto de átomos, mas arranjados em configurações diferentes por terem perdido/ganhado energia pelo processo de fotoemissão/fotorrecepção.
} 


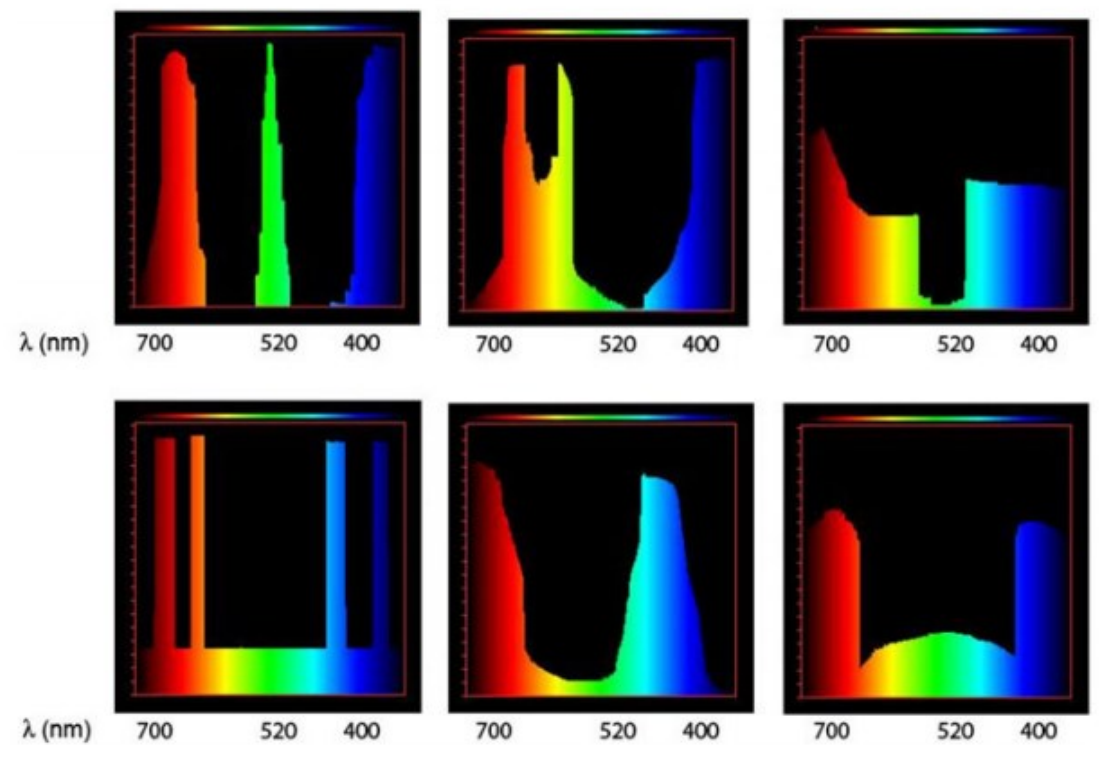

Fig. 3 - São mostrados 6 espectros de emissão diferentes, mas que produzem a mesma sensação visual da cor roxa (SCARINCI, 2014).

Neste contexto, uma questão pode ser levantada. O que nos ocorreu, ao longo de nossa evolução, para que nossa visão se comporte dessa maneira? A resposta satisfatória para esse questionamento, mais uma vez, é fruto da articulação de áreas distintas (e aparentemente, até desconexas) da ciência, a saber: astrofísica solar e biologia evolutiva.

\section{III.4 Astrofísica Solar e a evolução da visão humana}

A astrofísica solar nos fornece algumas pistas sobre como a vida na Terra evolui. Aparentemente, as condições para que a vida se desenvolva em um planeta é intimamente ligada às características da estrela desse sistema estelar e a distância entre ela e o planeta em questão. Dessa forma, se conceitua a noção de zona habitável, ou zona de Goldilocks, cujas principais características devem ser a presença de água no estado líquido, a presença de atmosfera viável e a temperatura amena (WILLIAMS, 2002). No caso particular do nosso sistema solar, o único planeta completamente dentro da zona habitável é a Terra. Marte e Vênus são intermitentes (ora estão dentro ora fora da zona habitável), o que faz alguns imaginarem que eles um dia já foram habitáveis ou ainda serão (SCHULZE-MAKUCH, 2002; LANDIS, 2003; PAULINO-LIMA, 2010).

Uma vez estabelecidas as condições mínimas para o desenvolvimento da vida, iniciase o processo natural da evolução - em tese. Toda a biota tende a se adaptar a condições ambientais e, no caso particular da visão humana, o que se observa é que ela se especializou na banda do espectro eletromagnético mais emitido pelo Sol (vide Fig. 4). 


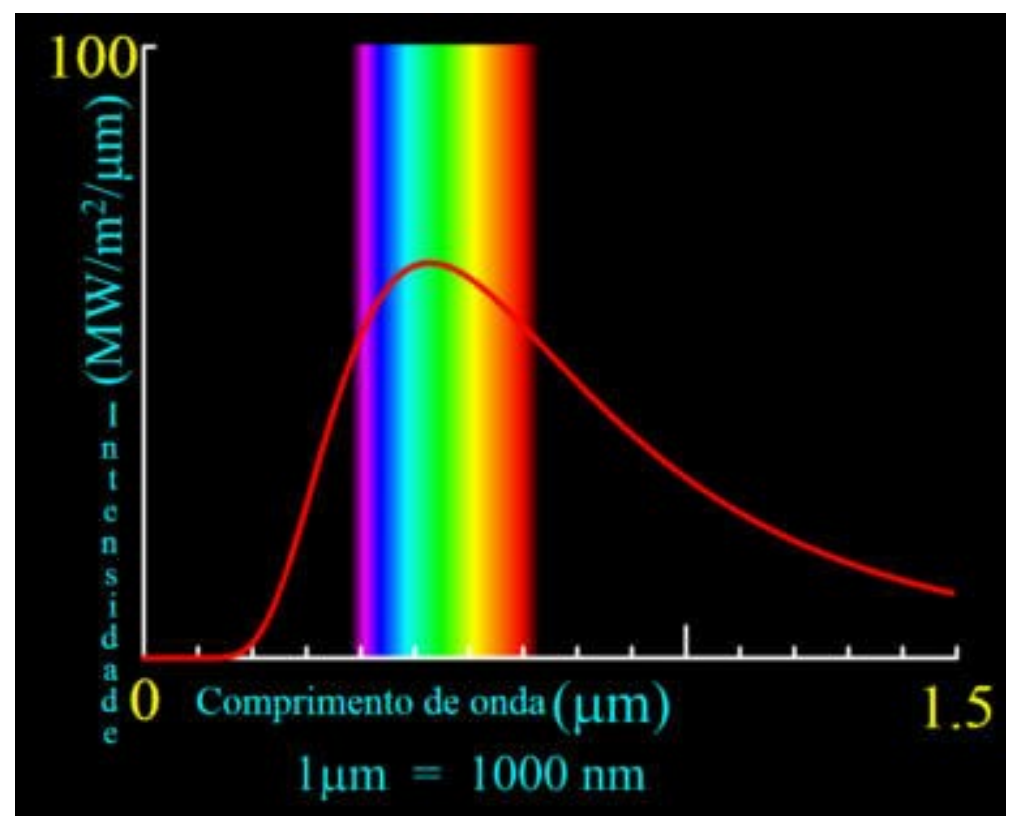

Fig. 4 - Intensidade luminosa solar versus comprimento de onda. Retirado do simulador Radiação do Corpo Negro do site phet.colorado (PHET, 2017). Curva para 5700 $K$.

Uma evidência disso é que a região onde acontece o pico de emissão solar, por volta de $500 \mathrm{~nm}$ (comprimento de onda que corresponde ao verde) (ECHER; SOUZA; SCHUCH, 2001), também é a região de máxima sensibilização da rodopsina (entre 505 e 510nm) e também coincide com um dos picos de maior sensibilização da iodopsina (por volta de 560nm) (WALD, 1955).

Reconstruindo nossos prováveis estágios evolutivos, somos levados a crer que um antepassado, ainda que remoto, da espécie humana, pelo processo de variabilidade genética, foi capaz de enxergar outras bandas do espectro eletromagnético. Entretanto, essa capacidade não constituía uma vantagem adaptativa e esses genes foram excluídos nas próximas gerações. Apesar de ser impossível reconstituir a visão de um ancestral fossilizado e verificar empiricamente essa hipótese, argumentos dessa natureza são razoáveis, uma vez que são corolários de uma teoria sólida e amplamente testada. Contudo, é preciso muita cautela ao afirmar categoricamente que há forte correlação entre estruturas biológicas e ambiente natural. Um exemplo formidável para ilustrar essa situação é a constituição das clorofilas de organismos fotossintetizantes no planeta Terra.

Plantas, algas e outros fotossintetizantes utilizam-se de uma estrutura conhecida como clorofila para realizar fotossíntese. Nesses organismos, sua maior fonte de energia advém dessa atividade. Ao observar o espectro de emissão solar, observamos que o pico de emissão acontece na região de 500nm. Logo, para uma estrutura biológica fotossintetizante, absorver nessa região oferece maior adaptabilidade, uma vez que, em tese, haveria maior disposição energética. Entretanto, o que se observa é que nenhuma clorofila é capaz de 
absorver ondas eletromagnéticas (ou absorve muito pouco) nesta faixa (vide Fig. 5) (DE MELO JÚNIOR, 2014). Essa surpreendente observação, nos serve como lembrete de que a evolução não acontece de maneira linear e nem produz, necessariamente, espécies mais "perfeitas".

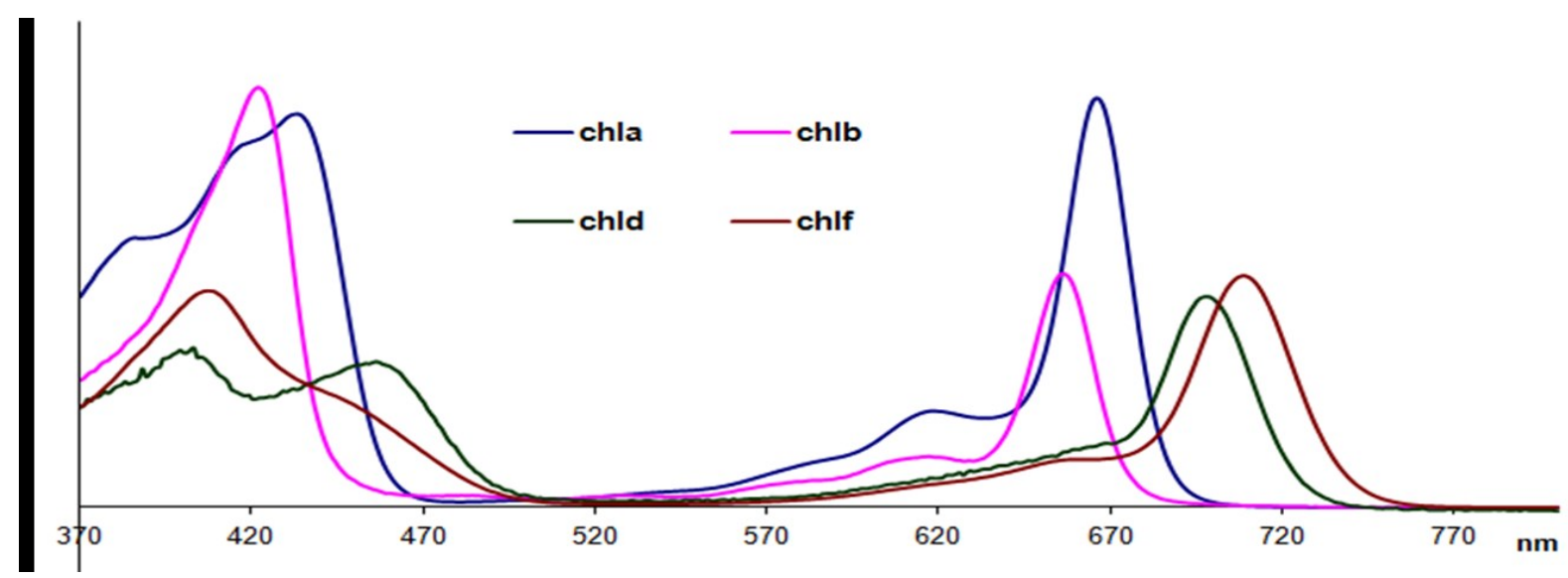

Fig. 5 - Representação da absorção versus comprimento de onda das quatro clorofilas encontradas em organismos fotossintetizantes. Clorofila A está representada pela curva azul (chla), a B pela cor rosa (cflb), a D pela cor verde (cfld) e a F pela cor vermelha (chlf) (KRIEDEMANN, 2010).

\section{Considerações finais}

A segmentação excessiva de conceitos escolares concernentes às ciências da natureza pode conduzir a uma série de equívocos, tanto por parte do estudante quanto do professor. A inabilidade da escola e de seus partícipes de articular conhecimentos correlatos pode ser atribuída, em parte, ao desconhecimento de exemplos, como o descrito neste trabalho. Em particular, conceitos da teoria da evolução biológica são escassamente utilizados fora do contexto da disciplina de Biologia e quando utilizados incorre-se em uma série de equívocos disseminados pelo senso comum.

Neste contexto, trabalhos que revelam a íntima relação entre descrições puramente físicas e as de caráter biológico são bem vindas (LIMA, 2016). Não se vê, por exemplo, em muitos livros de ensino médio uma descrição pormenorizada e bem balizada sobre sistemas biofísicos, em geral. Em nível de ensino superior, aparentemente, essa problemática é revelada mais vezes (RESNICK, 1987; BIZZO, 1991). Contudo, não parecem ser o foco das abordagens.

Ao se ensinar conceitos de física ondulatória, especialmente no que concerne a ondas eletromagnéticas, os professores que baseiam suas aulas nos referidos livros didáticos tendem a simplificar demasiadamente o funcionamento da visão humana e, quando muito, concentram-se na descrição óptica dos problemas de visão. Essa natureza de abordagem pode 
conduzir o estudante a entender que uma descrição física sobre um fenômeno é o fenômeno em si, o que é um disparate. Essa escolha, em boa medida, é justificada pelo considerável incremento de complexidade quando se leva em conta fenômenos biofísicos, bioquímicos e psiconeurais na descrição do funcionamento da visão humana. O que esse trabalho propôs é que ao se utilizar adequadamente conceitos de evolução biológica como eixo integrador e articulador entre áreas de conhecimentos distintas, mas correlatas - no caso descrito aqui, as disciplinas de Física e Biologia - os estudantes envolvidos no processo de aprendizagem podem ter o vislumbre de que os conhecimentos adquiridos em disciplinas diversas podem, e de fato devem, ser articulados para uma compreensão satisfatória de diversos fenômenos naturais reais.

Evidentemente, não foi nossa intenção esgotar o tema - que é bastante rico, diga-se. Entretanto, reconhecemos que ao não sugerir metodologias de aplicação o trabalho se limita a produção das bases teóricas sobre as quais um educador científico pode produzir seus próprios métodos. Este é um horizonte que gostaríamos de explorar em trabalhos ulteriores, especialmente sobre os aspectos didáticos que dizem respeito ao termo "luz" e como é empregado no ensino de física. De fato, não produzimos integralmente uma estratégia didática interdisciplinar. O trabalho é apenas inspirado na ideia de interdisciplinaridade trazida por Japiassú (1976) pelo pragmatismo que o autor traz e a ressonância que encontramos como nossa própria prática. A nossa expectativa é que este trabalho possa incentivar a confecção de estratégias interdisciplinares que se valem dessa discussão. $\mathrm{Na}$ expectativa de que esse trabalho possa inspirar colegas professores a enriquecerem sua prática e oportunizar a seus estudantes experiência educacionais mais significativas, colocamo-nos à disposição para os diálogos que podem ser suscitados por nosso trabalho.

\section{Referências}

ABRANTES, P. C. C. A metodologia de JC Maxwell e o desenvolvimento da teoria eletromagnética. Caderno Brasileiro de Ensino de Física, v. 5, p. 58-75, 1988.

AULER, D.; DELIZOICOV, D. Alfabetização científico-tecnológica para quê? Ensaio Pesquisa em Educação em Ciências, Belo Horizonte, v. 3, n. 2, p. 122-134, 2001.

BIZZO, N.; EL-HANI, C. N. O arranjo curricular do ensino de evolução e as relações entre os trabalhos de Charles Darwin e Gregor Mendel. Filosofia e História da Biologia, v. 4, n. 1, p. 235-257, 2009.

BIZZO, N. M. V. Ensino de evolução e história do darwinismo. 1991. Tese (Doutorado) Universidade de São Paulo.

BRASIL Parâmetros Curriculares Nacionais: ensino médio. Brasília: Ministério da 
Educação, 1999.

CESCHIM, B.; DE OLIVEIRA, T. B.; DE ANDRADE CALDEIRA, A. M. Teoria sintética e síntese estendida: uma discussão. A reforma do ensino médio e a implantação do Enem no Brasil1. Desafios, v. 65, n. 11, p. 46-115, 2004.

DE MELO JÚNIOR, R. P. et al. Qual é a influência da cor da luz na fotossíntese? Caderno Brasileiro de Ensino de Física, v. 32, n. 1, p. 287-290, 2014.

DOLGIN, E. The myopia boom. Nature, v. 519, n. 7543, p. 276, 2015.

DOS SANTOS, W. L. P. Educação CTS e cidadania: confluências e diferenças. Amazônia: Revista de Educação em Ciências e Matemáticas, v. 9, n. 17, p. 49-62, 2012.

ECHER, E.; SOUZA, M. P.; SCHUCH, N. J. A Lei de Beer aplicada na atmosfera terrestre. Revista Brasileira de Ensino de Física, v. 23, n. 3, 2001.

GUYTON, A. C.; HALL, J. E.; GUYTON, A. C. Tratado de fisiologia médica. Elsevier Brasil, 2006.

HECHT, E. Geometrical optics. Chapter, v. 5, p. 149-242, 1988.

HEYES, D. J.; HUNTER, C. N. Making light work of enzyme catalysis: protochlorophyllide oxidoreductase. Trends in biochemical sciences, v. 30, n. 11, p. 642-649, 2005.

JAPIASSU, H. Interdisciplinaridade e patologia do saber. Rio de Janeiro: Imago, 1976.

KRIEDEMANN, P. Chlorophyll absorption and photosynthetic action spectra. Plants in action adaptation in nature, performance in cultivation. Editors BJ Atwell, P. Kriedemann, and GN Colin. Macmillan Education Australia Pty Ltda., Melbourne, Australia, 2010.

LANDIS, G. A. Astrobiology: the case for Venus, 2003.

LANGER, H. Biochemistry and physiology of visual pigments, 1973.

LIMA, C. C. S.; DOS SANTOS, M. S. Astrobiologia como eixo integrador do ensino de ciências e biologia: como extraterrestes podem nos auxiliar no estudo da vida na terra, 2016.

MAYR, E. O que é a evolução. Rocco, 2009. 
MORGAN, R. W.; SPEAKMAN, J. S.; GRIMSHAW, S. E. Inuit myopia: an environmentally induced" epidemic"?. Canadian Medical Association Journal, v. 112, n. 5, p. 575, 1975.

MOSER, C. C.; PAGE, C. C.; DUTTON, P. L. Darwin at the molecular scale: selection and variance in electron tunnelling proteins including cytochrome c oxidase. Philosophical Transactions of the Royal Society of London B: Biological Sciences, v. 361, n. 1472, p. 1295-1305, 2006.

NASSAU, K. The Physics and Chemistry of Color: the fifteen causes of color. $2^{\text {nd }}$ Edition. ISBN 0-471-39106-9. Wiley-VCH, July 2001. p. 496, 2001.

NGO, C. et al. Does sunlight (bright lights) explain the protective effects of outdoor activity against myopia?. Ophthalmic and Physiological Optics, v. 33, n. 3, p. 368-372, 2013.

OKUNO, E.; YOSHIMURA, E. M. Física das radiações. Oficina de Textos, 2016.

OYAMADA, M. K. Fototransdução: ativação, inativação e adaptação. RBM Revista Brasileira de Medicina, v. 20, p. 11, 2015.

PAULINO-LIMA, I. G.; LAGE, C. de A. S. Astrobiologia: definição, aplicações, perspectivas e panorama brasileiro. Boletim da Sociedade Astronômica Brasileira, v. 29, n. 1, p. 14-21, 2010.

PHET, COLORADO. Disponível em: < https://phet.colorado.edu/pt/simulation/blackbodyspectrum>. Acesso em: 25 set. 2017.

PURKYNĚ, J. E. Beobachtungen und versuche zur physiologie der sinne. In Commission der JG Calve'schen Buchhandlung, 1823.

RESNICK, R.; HALLIDAY, D.; WALKER, J. Fundamentos de física. Continental, 1987.

SANDOVAL, J. D.; SALINAS, J. A sensação de cor: um problema da Física? Algumas experiências para sala de aula. Caderno Brasileiro de Ensino de Física, v. 7, n. 3, p. 183$195,1990$.

SCARINCI, A. L.; MARINELI, F. O modelo ondulatório da luz como ferramenta para explicar as causas da cor. Revista Brasileira de Ensino de Física, v. 36, n. 1, p. 1309, 2014. 
SCHRODINGER, E. What is life?: The physical aspect of the living cell. 1946.

SCHULZE-MAKUCH, D.; IRWIN, L. N. Reassessing the possibility of life on Venus: proposal for an astrobiology mission. Astrobiology, v. 2, n. 2, p. 197-202, 2002.

TIDON, R.; VIEIRA, E. O ensino da evolução biológica: um desafio para o século XXI. ComCiência, n. 107, p. 0-0, 2009.

USBERCO, J.; SALVADOR, E. Química. Volume único. Editora Saraiva. 2003.

WALD, G.; BROWN, P. K.; SMITH, P. H. I. The Journal of general physiology, v. 38, n. 5, p. 623-681, 1955.

WILLIAMS, D. M.; POLLARD, D. Earth-like worlds on eccentric orbits: excursions beyond the habitable zone. International Journal of Astrobiology, v. 1, n. 1, p. 61-69, 2002.

ZIMMERMANN, E.; CARLOS, J. G. Interdisciplinaridade e ensino de física: Quais as possibilidades. In: Simpósio Nacional de Ensino de Física, XVI, 2005. Anais... p. 425-3.

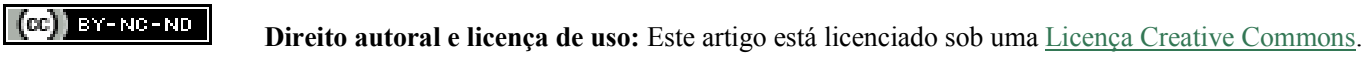

